\title{
PENGGUNAAN POLA KALIMAT KAGIRI DAN KAGIRI DA DALAM BAHASA JEPANG (ANALISIS STRUKTUR DAN MAKNA)
}

\author{
${ }^{\text {a }}$ Mellati Riandi Putri, ${ }^{\text {b }}$ Wagiati \\ $a, b$ Universitas Padjadjaran \\ e-mail: mellati11001@mail.unpad.ac.id
}

\begin{abstract}
The purpose of this research is to find the way of using kagiri and kagiri da as sentence patterns in Japanese. The type of this research is qualitative research with descriptive method. The data was taken from Japanese online news website, Asahi Shinbun which published on early December 2020 that contain sentences that using kagiri and kagiri da sentence pattern. There are 21 data gathered from Asahi Shinbun, and based on the part of speech that formed with kagiri and kagiri da sentence pattern, there are ten data were classified as noun, nine data were classified as verb, and 2 data classified as adjective. The kagiri sentence pattern used as conjunction when formed with noun and verd with semantic meaning as "while" with certain condition or terms, and used as suffix when formed with noun which containing number or time with semantic meaning of limitation of something. While the kagiri da sentence pattern only formed with adjectives and always in the end of the sentence with semantic meaning of describing a certain level of the speaker feelings. The kagiri sentence pattern have a lot of variations such as formed with joshi in ni kagiri pattern, ni kagitte pattern, and ni kagiru pattern. The further research through another data source such as corpus may needed to find another purpose of this sentence pattern.
\end{abstract}

Keywords: syntax, semantic, verb, kagiri, kagiri da 


\section{PENDAHULUAN}

Dalam mempelajari bahasa asing, terkadang pembelajar bahasa asing kesulitan untuk membedakan fungsi dan penggunaan pola kalimat yang bentuknya hampir serupa. Bahasa Jepang memiliki banyak pola kalimat dengan bentuk yang hampir serupa ataupun pola berbeda dengan makna yang sama sehingga terkadang sulit ditentukan penggunannya oleh pembelajar bahasa Jepang.

Fenomena tersebut dapat diperhatikan dari hasil penelitian mengenai perbedaan penggunaan setsuzokushi (konjungsi) aida dan aida ni dalam bahasa Jepang oleh Muthma'innah, Rahayu, dan Hartati (2020). Dari hasil penelitian kedua setsuzokusi tersebut diketahui bahwa setsuzokushi aida dan aida ni memiliki rumus pola kalimat yang sama, hanya saja dibedakan oleh partikel $n i$ sebagai penanda titik waktu. Kurun waktu yang ditunjukkan oleh setsuzokushi aida adalah sama antara anak klausa dengan induk klausanya. Sementara itu, pada setsuzokushi aida ni aktifitas yang ditunjukkan pada induk klausa dilaksanakan di sela waktu anak klausa. Dapat dikatakan bahwa pada setsuzokushi aida ni, sebuah aktivitas dilakukan dengan waktu yang berbeda, dalam waktu yang singkat, dan tidak secara berkelanjutan. Jadi dapat disimpulkan bahwa partikel $n i$ memiliki pengaruh yang besar dalam menentukan makna kalimat.

Penelitian mengenai pola kalimat dengan masalah yang serupa juga dipaparkan oleh Bahudin (2013). Pada penelitiannya yang membahas mengenai penggunaan pola kalimat koto ni suru dan koto ni naru dalam bahasa Jepang, Bahudin (2013) menyimpulkan bahwa pola kalimat koto ni suru dan koto ni naru mempunyai pola dan fungsi yang sama, yaitu untuk menyampaikain kalimat dengan makna "memutuskan untuk ...". Meskipun begitu, perbedaan pada kedua pola kalimat tersebut terletak pada subjek yang melakukan aktivitas. Pola kalimat koto ni suru berkonotasi bahwa keputusan yang diambil ditentukan oleh diri sendiri, sementara pola kalimat koto ni naru berkonotasi bahwa menerima atau melakukan sesuatu berdasarkan keputusan dari orang lain (ditetapkan oleh orang lain).

Pada kedua penelitian di atas, dapat diperhatikan bahwa sedikit perbedaan pada suatu pola kalimat ternyata dapat menyebabkan perbedaan makna dalam bahasa Jepang. Berdasarkan fenomena tersebut, penulis tertarik untuk menganalisis penggunaan kagiri dalam pola kalimat bahasa Jepang. Tujuan dari penelitian ini adalah untuk mendesrikpsikan penggunaan pola kalimat $\sim$ kagiri dan $\sim$ kagiri da dengan menganalisis struktur dan maknanya. Penulis mengharapkan penelitian ini dapat menambah ilmu pengetahuan mengenai penggunaan pola kalimat dalam bahasa Jepang bagi pembelajar bahasa Jepang.

Tata bahasa atau grammar didefinisikan oleh Richards dan Schmidt (2010) sebagai sebuah deskripsi mengenai struktur dari sebuah bahasa mengkombinassikan unit linguistik seperti kata dan frasa untuk menghasilkan kalimat dalam bahasa. Biasanya pola kalimat mempertimbangkan arti dan fungsi yang dimiliki kalimat dalam sistem bahasa secara keseluruhan.

Kridalaksana (2008) mendefinisikan pola kalimat sebagai konsep sintaksis yang mencakup konstruksi seperti indikatif, imperatif, dan sebagainya. Dalam konteks pembelajaran bahasa, pola kalimat merupakan pola seperti $\mathrm{N}$ (nomina) + V (verba) + N (Nomina) untuk mendefinisikan pola pada kalimat "Adik membaca buku". Richards dan Schmidt (2010: 523) juga menambahkan bahwa dalam pengajaran bahasa, pola kalimat mempertimbangkan pola gramatika dasar dari kalimat dalam bahasa yang diajarkan, yang mana dapat digunakan sebagai acuan untuk membentuk kalimat lain. 
Terdapat dua cara untuk menganalisis pola kalimat dalam pembelajaran bahasa, yaitu dengan menganalisis strukturnya, dan menganalisis maknanya. Chaer (2012) menjelaskan bahwa sintaksis adalah salah satu bagian dari ilmu lingustik yang mengkaji struktur sintaksis (mencakup fungsi, kategori, dan peran sintaksis) beserta kelengkapan strukturnya, satuan-satuan sintaksis (berupa frasa, klausa, kalimat dan wacana), serta hal lain yang berkaitan dengan sintaksis seperti aspek, modus, dan sebagainya. Dalam bahasa Jepang, sintaksis disebut dengan istilah tougoron. Nitta (dalam Sutedi, 2012) menjelaskan bahwa ruang lingkup sintaksis yaitu membahas mengenai kalimat yang mencakup jenis dan fungsi, unsur pembentuk, serta struktur dan makna.

Berdasarkan struktur pembentukan dan jumlah klasusanya, Sutedi (2011) menggolongkan kalimat

menjadi tanbun (kalimat tunggal) dan fukubun (kalimat majemuk). Dalam fukubun (kalimat majemuk), terdapat tiga macam informasi yang ada di dalamnya, yaitu shusetsu (induk kalimat atau klausa utama), juusetsu (anak kalimat atau klausa tambahan), dan seibunsetsu (klausa pelengkap atau menerangkan subjek atau objek).

Selanjutnya pola kalimat dapat dianalisis berdasarkan maknanya melalui cabang ilmu linguistik yang disebut dengan semantik. Dalam bahasa Jepang, semantik dikenal dengan istilah imiron. Sutedi (2012) menjelaskan bahwa imiron membahas mengenai makna, dengan objek kajian antara lain makna kata (go no imi), relasi makna (go no imi kankei), makna frasa ( $k$ u no imi) dan makna kalimat (bun no imi).

Secara umum, menurut Yasuda (1980) tango (kata) dalam bahasa Jepang terdiri atas beberapa kelas kata yang disebut dengan hinshi. Kemudian, Murakami (dalam Sudjianto dan Dahidi, 2012) menggolongkan hinshi (kelas kata) menjadi dua bagian, yaitu kata yang dapat berdiri sendiri dan dapat menunjukkan arti tertentu (kemudian dikenal dengan istilah jiritsugo) dan kata yang tidak memiliki arti tertentu tanpa didampingi kata lain yang dapat berdiri sendiri (kemudian dikenal dengan istilah fuzokugo).

Murakami kemudian mengklasifikasikan jiritsugo berdasarkan ada atau tidaknya konjugasi atau deklinasi pada sebuah kata. Kelompok kelas kata yang mengenal kojugasi atau deklinasi terdiri dari doushi (verba), keiyoushi (adjektiva-i), dan keiyoudoushi (adjektiva-na), selanjutnya kelompok kelas kata yang tidak mengenal konjugasi atau deklinasi terdiri dari meishi (nomina), rentaishi (pronomina), fukushi (adverbia), kandoushi (interjeksi), dan setsuzokushi (konjungsi).

Sementara itu, fuzokugo hanya terbagi atas dua jenis, yaitu fuzokugo yang mengalami konjugasi, yaitu jodoushi (verba bantu) dan fuzokugo yang tidak mengalami konjugasi, yaitu joshi (partikel).

Secara harfiah, Taniguchi (2008: 233) mendefinisikan pengertian kagiri dalam dua makna, yaitu yang pertama bermakna batas atau hingga, dan yang kedua bermakna abadi, kekal, terus-menerus, atau tidak ada habisnya. Makino dan Tsutsui (2001) menjelaskan bahwa kata kagiri dapat berupa konjungsi maupun akhiran, dan dapat diawali oleh meishi dan doushi sebelumnya.

Setsuzokushi (konjungsi) didefinisikan oleh Ogawa (dalam Sudjianto dan Dahidi, 2012) dalam berbagai sudut pandang. Berdasarkan artinya, setsuzokushi merupakan kelas kata yang menunjukkan hubungan antara dua inti ungkapan. Berdasarkan cara pemakaiannya setsuzokushi didefinisikan sebagai kelas kata ynag digunakan di antara dua kata, dua bunsetsu, dua $k u$, dua bun atau lebih. Sementara berdasarkan fungsinya, setsuzokushi digunakan untuk mengembangkan suatu ungkapan. 
Meishi (nomina) didefinisikan oleh Matsuoka (dalam Sudjianto dan Dahidi, 2012) sebagai kata yang menyatakan menyatakan benda, orang, peristiwa dan sebagainya. Meishi tidak mengalami konjugasi. Takano (dalam Sudjianto dan Dahidi, 2012) membagi meshi menjadi lima macam, yaitu: 1. Futsuu meishi, yang menyatakan nama benda, barang, dan sebagainya; 2. Коуии meishi, yang menyatakan nama orang, negara, buku, dan sebagainya; 3. Suushi yang menyatakan jumlah, bilangan, urutan, dan sebagainya; 4. Keishiki meishi, yang menyatakan fungsi formalitas tanpa memiliki arti yang sebenarnya seperti kata koto, wake, dan hazu; 5. Daimeshi, yang dalam bahasa Indonesia serupa dengan pronomina atau kata ganti orang.

Doushi (verba) dalam bahasa Jepang mengalami konjugasi. Kridalaksana (2008) menjelaskan konjugasi sebagai pengklasifikasian verba menurut bantuk infleksinya atas kala, persona dan jumlah. Menurut Masaso (dalam Sudjianto dan Dahidi, 2012) bentuk kata konjugasi dalam bahasa Jepang yang disebut dengan istilah katsuyoukei diklasifikasikan menjadi enam macam dengan penjelasan sebagai berikut: 1. Mizenkei, menyatakan aktivitas yang belum dilakukan atau belum terjadi. Bentuk mizenkei diikuti oleh $u$, you, nai, seru, saseru, reru, dan rareru; 2. Renyoukei, menyatakan kelanjutan dari sebuah aktivitas. Bentuk renyoukei diikuti oleh masu, ta, da, tai, te, atau nagara; 3. Shuushikei, merupakan bentuk dasar verba yang digunakan pada saat mengakhiri pembicaraan. Bentuk shuusikei dapat diikuti oleh kata ka dan kara; 4. Rentaikei, merupakan bentuk yang diikuti taigen seperti toki dan koto. Bentuk ini dapat pula diikuti oleh youda, bakari, dan sebagainya; 5. Kateikei, digunakan untuk menyatakan pengandaian. Bentuk kateikei diikuti oleh ba; 6. Meireikei, merupakan bentuk yang menyatakan perintah.

Dalam bahasa Jepang, terdapat dua jenis adjektiva, yaitu I-keiyoushi dan $\mathrm{Na}$ keiyoushi. I-keiyoushi atau yang sering juga disebut sebagai keiyoushi didefinisikan oleh Kitahara (dalam Sudjianto dan Dahidi, 2012) sebagai kelas kata yang menyatakan sifat atau keadaan sesuatu, dengan sendirinya dapat menjadi predikat dan dapat mengalami perubahan bentuk. Shimizu (dalam Sudjianto dan Dahidi, 2012) menjelaskan bahwa i-keiyoushi terbagi atas 2 jenis, yaitu: 1) Zokkusei keiyoushi, merupakan kelompok adjektiva-I yang menyatakan sifat atau keadaan secara objektif, seperti nagai (panjang), akai (merah) dan sebagainya. 2. Kanjyou keiyoushi, merupakan kelompok adjektiva-I yang menyatakan perasaan atau emosi secara subjektif, seperti kowai (takut), ureshii (senang) dan sebagainya.

Selanjutnya na-keiyoushi atau yang sering juga disebut sebagai keiyoudoushi didefinisikan oleh Sutedi (2011) sebagai kelas kata yang dengan sendirinya dapat membentuk sebuah bunsetsu, dapat berubah bentuknya, dan bentuk shuusikei-nya berakhir dengan da dan desu. Shimizu (dalam Sudjianto dan Dahidi, 2012) membagi $i$-keiyoushi dalam jenis yang serupa dengan i-keiyoushi yaitu: 1) Keiyoudoushi yang menyatakan sifat, contohnya kireida (indah/cantik), sawayakada (segar), dan sebagainya. 2) Keiyoudoushi yang menaytakan perasaan, seperti kiraida (benci), fushigida (aneh), dan sebagainya.

\section{METODE PENELITIAN}

Penelitian ini menggunakan metode analisis deskriptif kuantitatif. Sudaryanto (2015) menjelaskan bahwa penelitian deskriptif menjabarkan fenomena bahas fenomena bahasa dan dianalisis untuk mendapatkan pemahaman. Selanjutnya pada penelitian kuantitatif, tidak digunakan prosedur statistik untuk meneliti permasalahannya. 
Data pada penelitian ini diperoleh menggunakan metode simak yang dijelaskan oleh Mafsun (2012) digunakan untuk menyimak penggunaan bahasa dengan teknik dasar sadap, dan selanjutnya menggunakan teknik lanjutan berupa teknik catat. Data dari penelitian ini berasal dari situs berita daring Asahishinbun dalam bahasa Jepang yang diunggah pada awal Desember 2020.

Metode yang digunakan untuk menganalisis data adalah metode agih dengan teknik dasar berupa teknik bagi unsur langsung yang dijelaskan oleh Mafsun (2012) sebagai metode yang membagi satuan lingual data menjadi beberapa bagian atau unsur. Data yang telah dikumpulkan kemudian dikelompokkan berdasarkan kelas kata yang muncul sebelum kagiri berdasarkan teori kelas kata oleh Murakami untuk selanjutnya dianalisis perbedaan yang ada pada tiap data.

Hasil penelitian kemudian dirumuskan dengan menggunakan kata-kata biasa atau metode informal.

\section{PEMBAHASAN}

Pada peneitian ini ditemukan 21 data berupa kalimat yang menggunakan pola $\sim$ kagiri dan $\sim$ kagiri da, dengan rincian terdapat 10 data tergolong dalam kelas kata meishi, 9 data tergolong dalam kelas kata doushi, dan 2 data tergolong dalam kelas kata keiyoushi. Berikut analisis pola kalimat kagiri berdasarkan pada beberapa contoh data.

\section{A. Didahului oleh Meishi (nomina)}

\section{Data 1:}

1 日 5 食限りで 7 千円相当の肩ロースを格安で出す。

/Ichinichi goshoku kagiri de nana sen en soutou no kata roosu wo kakuyasu de dasul

'Dalam satu hari kami menyediakan hanya lima porsi daging has senilai tujuh ribu yen dengan harga murah.'

Dari segi struktur, pada data 1 dapat diperhatikan bahwa sebelum kagiri, terdapat kata go shoku 'lima porsi' yang tergolong pada kelas kata meishi berupa suushi atau nomina berupa bilangan yang diikuti dengan sufiks "porsi". Pola kagiri pada kalimat di atas bukanlah sebagai setsuzokushi (konjungsi), melainkan sebagai akhiran yang melekat pada nomina. Hal tersebut juga dapat diperhatikan dari bentuk kalimat yang berupa tanbun. Selanjutnya dari segi makna, kata kagiri pada kalimat ini memiliki makna "hanya" atau berupa batasan terhadap sesuatu.

Data 2:

明治神宮野球場（東京都新宿区）で野球ファンや関係者に親しまれて きた、そば・うどんの「水明亭」が今年限りで閉店する。

IMeijijingu yakyuuba (Toukyou-to Shinjuku-ku) de yakyuu fan ya kankeisha ni shitashimaretekita, soba udon no 「Suimeitei」 ga kotoshi kagiri de heitensuru./

'Restoran soba dan udon "Suimeitei" yang terkenal oleh penggemar bola kasti dan staff yang berada di stadium Meijijingu akan ditutup, berakhir tahun ini.' 
Pada data 2, dapat diperhatikan bahwa kata kagiri diikuti oleh meishi berupa waktu yaitu kotoshi 'tahun ini'. Sama seperti pada data 1, pola kalimat kagiri pada data 2 bukanlah konjungsi, melaikan berfungsi sebagai akhiran yang melekat pada nomina. Pola kagiri pada data 2 juga memiliki makna "akhir" atau batas waktu.

Data 3:

肉体を持つ人間である限り、私たちも当時の若者と同じ欲求を抱き得る。 INikutai wo motsu ningen de aru kagiri, watashi tachi mo touji no wakamono to onaji yokkyuu wo dakieru.l

'Selama kami masih manusia yang memiliki tubuh, kami pun memiliki keinginan yang sama seperti anak muda pada masa itu.'

Kata ningen 'manusia' yang mendahului pola kagiri pada data 3 tergolong pada kelas kata meishi berupa futsuu meishi. Meishi pada kalimat ini diikuti oleh jodoushi berupa dearu. Pada data 3, pola kagiri menjadi setsuzokushi dalam kalimat. Hal tersebut juga dapat diperhatikan dari bentuk kalimat 3 yang merupakan kalimat majemuk. Berbeda dengan data 1 dan data 2, makna dari pola kagiri dari data 3 merupakan "selama" dengan kondisi atau ketetapan tertentu.

\section{B. Didahului oleh Doushi (verba)}

Data 4:

コロナ禍が落ち着かない限り、さらに厳しくなる。

/Korona-ka ga ochitsukanai kagiri, sara ni kibishikunaru./

'Selama bencana Corona belum tenang, malah semakin sulit.'

Pada data 4, terdapat kata ochitsukanai 'tidak tenang' yang tergolong dalam kelas kata doushi dengan bentuk futsuu-kei dengan tambahan jodoushi atau verba bantu nai. Pola kagiri pada data 4 berfungsi sebagai setsuzokushi, ditandai dengan struktur kalimat pada data 4 yang berupa kata majemuk. Makna pola kagiri pada data 4 sama dengan makna yang terdapat pada data 3, yaitu "selama" dengan kondisi atau ketetapan tertentu.

Data 5:

「体力が残る限り、歴史の後ろにある普通の人たちの話を伝えたい」 と話した。

I 「Tairyoku ga nokoru kagiri, rekishi no ushiro ni aru futsuu no hitotshi no hanashi wo tsutaetai to hanashita. 」/

" "Selama masih tersisa tenaga, saya ingin menyampaikan kisah mengenai orang-orang yang berada di blakang sejarah." katanya.'

Kata nokoru 'tersisa' yang berada sebelum kata kagiri tergolong dalam kelas kata doushi dalam bentuk futsuu-kei atau bentuk kamus. Pola kagiri pada data 5 juga berfungsi sebagai setsuzokushi seperti pada data 4. Pola kalimat kagiri pada data 5 juga memiliki makna "selama" dengan kondisi atau ketetapan tertentu yang terdapat pada awal kalimat. 


\section{Didahului oleh Keiyoushi atau Keiyoudoushi (adjektiva)}

Data 6:

奥田町長は「頼もしい限り。ゴールまで笑顔で走りきってほしい」と 激励して送り出した。

IOkuda chouchou 「tanomoshii kagiri. Gooru made egao de hashirikitte hoshii」 to gekirei shite okuridashita.l

Walikota Okuda menyemangati dan mengantarkan peserta, "Saya merasa sangat bangga. Saya ingin peserta dapat berlari hingga garis akhir dengan senyuman.",

Pada data 6, terdapat kata tanomoshii 'bangga atau dapat diandalkan' yang tergolong pada kelas kata keiyoshi sebelum pola kagiri. Pada data 6, pola kagiri bukanlah setsuzokushi dan bukan pula berupa akiran. Pola kagiri yang diawali oleh adjketiva memiliki makna "merasa sangat..."

Data 7:

けがは仕方がないとは言え、役者がどんどん消えるのは寂しい限りだ。 IKega ga shikata ga nai to wa ie, yakusha ga dondon kieru no wa sabishii kagiri da.I

"Meskipun dibilang jika terluka apa boleh buat, tetapi saya merasa sangat kesepian karena pesumo sedikit demi sedikit berkurang."

Serupa dengan pola kagiri yang terdapat pada data 6, pada pola kagiri pada data 7 juga terdapat kata sabishii 'sepi atau sedih' yang tergolong pada kelas kata keiyoushi sebelum kata kagiri. Makna pola kalimat kagiri pada data 7 juga menyatakan perasaan seseorang atau "merasa sangat ...".

Pada data pola kalimat kagiri yang didahului oleh keiyoushi, ditemukan bahwa kagiri selalu diikuti oleh jodoushi berupa desu atau da dan kata kagiri selalu terletak pada akhir frasa atau akhir kalimat.

\section{SIMPULAN}

Berdasarkan penelitian terhadap data yang telah dianalisis, ditemukan beberapa perbedaan pola kalimat $\sim$ kagiri dan $\sim$ kagiri da baik dari segi kelas kata yang berada sebelum pola kalimat, struktur kalimat, dan maknanya.

Berdasarkan fungsi dan makna dari pola kalimat kagiri dan kagiri da, dapat diambil kesimpulan bahwa pola kalimat $\sim$ kagiri dapat berfungsi sebagai setsuzokushi (konjungsi) dengan kelas kata yang terdapat sebelumnya berupa meishi yang memiliki jyodoushi de aru atau de nai atau doushi dengan bentuk futsuu kei atau bentuk kamus. Makna dari pola kalimat kagiri sebagai setsuzokushi adalah "selama" dengan kondisi atau ketetapan tertentu yang terdapat pada awal kalimat.

Selanjutnya, pola kalimat kagiri berfungsi sebagai akhiran atau sufiks jika sebelumnya terdapat kata dengan kelas kata meishi berupa hitungan bilangan atau waktu. Pola kalimat $\sim$ kagiri sebagai sufiks memiliki makna batasan atau limit dari jumlah atau waktu. Terakhir, pola kalimat $\sim$ kagiri da hanya terdapat pada akhir kalimat dan hanya terdapat setelah kata yang berasal dari kelas kata adjektiva. Pola kalimat kagiri da memiliki makna menyampaikan perasaan pada tingkatan tertentu. 
Penulis menemukan banyak pola kalimat yang menggunakan kata kagiri, seperti pola kalimat $\sim$ ni kagiri dan $\sim$ ni kagitte. Penelitian dengan sumber data dengan lingkup lebih besar seperti korpus atau penelitian berbasis koprus dibutuhkan untuk menemukan penggunaan pola kalimat yang tepat bagi pembelajar bahasa Jepang.

\section{DAFTAR PUSTAKA}

Bahudin, Christy. (2013). Arti Dan Penggunaan Pola " Koto Ni Suru” Dan " Koto Ni Naru” Dalam Pola Kalimat Bahasa Jepang. Jurnal Elektronik Universitas Sam Ratulagi 2013 Vol. 1.

Chaer, Abdul. (2012). Linguistik Umum Edisi Revisi. Jakarta: Rineka Cipta.

Kridalaksasna, H. (2009). Kamus Linguistik. Jakarta: Gramedia Pustaka Utama.

Makino, S., \& Tsutsui, M. (2001). A Dictionary of Intermediate Japanese Grammar. Tokyo: The Japan Times.

Mafsun. (2012). Metode Penelitian Bahasa: Tahapan Startegi, Metode, dan Tekniknya Edisi Revisi. Jakarta: Rajawali Press.

Muthma'innah, A., Rahayu, Elly T., \& Hartati. (2020). Perbedaan Penggunaan Setsuzokushi Aida dan Aida Ni. J-Litera vol 2 (1) pp.36-45

Richards, J., \& Schmidt, R. (2010). Longman Dictionary of Language Teaching and Applied Linguistics Forth Edition. Great Britain: Pearson Education Limited.

Sudaryono. (2015). Metode dan Aneka Teknik Analisis Bahasa: Pengantar Penelitian Wahana Kebudayaan secara Linguistis. Yogyakarta: Sanata Dharma University Press.

Sudjianto, \& Dahidi, A. (2012). Pengantar Lingusitik bahasa Jepang. Jakarta: Keisant Blanc.

Sutedi, D. (2011). Dasar-Dasar Linguistik Bahasa Jepang. Bandung: Humaniora Press.

Taniguchi, G. (2008). Kamus Standar Bahasa Jepang-Indonesia. Jakarta: Dian Rakyat.

Yasuda. (1980). Nihon no Gengohaku Bunpou II. Tokyo: Taishuukan. 